\title{
Early docosahexaenoic and arachidonic acid supplementation in extremely-low-birth-weight infants
}

\author{
Daniel T. Robinson' ${ }^{1}$, Michael Caplan², Susan E. Carlson ${ }^{3}$, Rachel Yoder ${ }^{3}$, Karna Murthy ${ }^{1}$ and Brandy Frost ${ }^{2}$
}

BACKGROUND: Extremely-low-birth-weight (ELBW) infants accrue large deficits in docosahexaenoic acid (DHA) and arachidonic acid (ARA) and require improved supplementation strategies. We hypothesized that once daily DHA+ARA drops applied to buccal mucosa will increase blood levels.

METHODS: Thirty ELBW infants were randomized to receive DHA $20 \mathrm{mg} / \mathrm{kg} / \mathrm{d}$ + ARA 40 or $60 \mathrm{mg} / \mathrm{kg} / \mathrm{d}$ + ARA $120 \mathrm{mg} / \mathrm{kg} / \mathrm{d}$ or placebo within $72 \mathrm{~h}$ of age for $8 \mathrm{wk}$ duration. Red blood cell phospholipid levels of DHA (primary) and ARA (secondary) were measured at 2 and 8 wk of age.

RESULTS: Twenty-eight survivors with a median birth weight of $806 \mathrm{~g}$ completed dosing and sampling. Red blood cell levels were similar between the three groups at 2 wk (DHA: 4.62 wt\% (interquartile range (IQR) 4.1-5.5) for all, $P=0.29$ between groups; ARA: 21.1 wt\% (IQR 18.78-22.6) for all, $P=0.41$ between groups) and $8 w$ w (DHA: $6.0 w t \%$ (IQR 5.1-7.1) for all, $P=0.57$ between groups; ARA: $20.1 \mathrm{wt} \%$ (IQR 18.3-23.1) for all, $P=0.63$ between groups). DHA in all infants showed a median increase of $31 \%$ from 2 to $8 \mathrm{wk}(P<0.04)$. ARA levels did not significantly change over time $(P>0.6)$.

CONCLUSION: Daily buccal DHA and ARA supplements did not affect fatty acid levels in ELBW infants.

P reterm infants receive inadequate amounts of the longchain polyunsaturated fatty acids (LCPUFAs), docosahexaenoic acid (DHA, 22:6n - 3) and arachidonic acid (ARA, $20: 4 n-6)$, during hospitalization in the neonatal intensive care unit (NICU) (1). Insufficient provisions and low red blood cell (RBC) DHA and ARA levels have been associated with poor growth and increased risk of chronic lung disease and sepsis (2-4). Deficiencies also contribute to select short-term visual and developmental morbidities in preterm infants $(2,5,6)$.

Current formulations and delivery of parenteral and enteral nutrition to preterm infants in the NICU allow accumulation of significant deficits in DHA and ARA (7). The fully fed preterm infant absorbs $<40 \%$ of expected fetal accretion rates (8), and intravenous lipid emulsions (IVLEs) used in the United States are devoid of these LCPUFA (9). Although lactating women may be taking supplemental DHA, breast milk levels still fail to meet the preterm infant's demands (8). Extremely-low-birth-weight (ELBW) infants are at greatest risk of deficit (8).

The best mechanism of providing LCPUFA to preterm infants remains to be determined. Supplements should be provided with relative ease of administration, good tolerability, and ideally remain independent of an infant's physiologic status and ability to tolerate enteral feedings. This would also account for immature pancreatic function and diminished intestinal absorption (10). Oropharyngeal application of small volumes of breast milk for nonnutritive purposes has been incorporated into some clinical practices, can occur independent of feeding status, and results in systemic absorption of bioactive factors $(11,12)$. In addition, fatty acids have been safely applied and absorbed topically and to buccal and rectal mucosa as effective drug adjuvants (13-18). We therefore proposed the buccal administration of LCPUFA as a method of supplementation in a preterm population that depends on IVLE and may experience frequent interruptions in enteral feedings.

Correspondingly, we aimed to define the feasibility, efficacy, and tolerability of daily supplementation of DHA and ARA directly to the oral mucosa of ELBW infants. Our hypothesis is that this method would be a well-tolerated mechanism for raising systemic levels of LCPUFA after 8 wk of daily administration.

\section{RESULTS}

\section{LCPUFA Levels and Infant Characteristics}

LCPUFA supplementation with $20 \mathrm{mg} / \mathrm{kg} / \mathrm{d}$ or $60 \mathrm{mg} / \mathrm{kg} / \mathrm{d}$ DHA did not alter RBC phospholipid (PL) LCPUFA levels at 2 or $8 \mathrm{wk}$; levels were similar in all groups (Table 1). DHA increased over the sampling interval within all three groups $(P<$ $0.04)$ and increases were of similar magnitude between groups (Placebo: 31\%; Low: 38\%; High: 17\%; P = 0.4). Within assignment groups, ARA showed no significant increase between the sampling interval with no differences detected between groups (Placebo: 2.2\%; Low: 2.4\%; High: 3.2\%; $P>0.67$ within each group).

\footnotetext{
'Ann \& Robert H. Lurie Children's Hospital of Chicago and Department of Pediatrics, Feinberg School of Medicine, Northwestern University, Chicago, Illinois; ${ }^{2}$ Department of Pediatrics, NorthShore University HealthSystem, Pritzker School of Medicine, University of Chicago, Evanston, Illinois; ${ }^{3}$ Department of Dietetics and Nutrition, University of Kansas Medical Center, Kansas City, Kansas. Correspondence: Daniel T. Robinson (daniel-robinson@northwestern.edu) 


\section{Articles $\mid$ Robinson etal.}

Table 1. Red blood cell phospholipid fatty acid levels at 2 and 8 wk (median IQR) ${ }^{a}$

\begin{tabular}{|c|c|c|c|c|c|c|c|}
\hline Fatty acid & All, $n=28$ & Placebo, $n=10$ & Low dose, $n=9$ & High dose, $n=9$ & $P^{b}$ & Any DHA, $n=18$ & $P^{c}$ \\
\hline \multicolumn{8}{|l|}{$2 w k$} \\
\hline LA & $12.5(11.0,13.6)$ & $12.2(11.0,13.2)$ & $12.7(10.4,13.5)$ & $12.7(11.7,13.9)$ & 0.72 & $12.7(11.0,13.6)$ & 0.70 \\
\hline ARA & $21.1(18.8,22.6)$ & $21.6(20.2,23.0)$ & $19.3(17.6,22.5)$ & $20.3(18.9,21.3)$ & 0.41 & $19.1(18.8,22.5)$ & 0.20 \\
\hline $\mathrm{DHA}$ & $4.6(4.1,5.5)$ & $5.3(4.8,5.6)$ & $4.0(4.0,4.8)$ & $4.5(4.4,5.2)$ & 0.29 & $4.4(4.0,5.2)$ & 0.17 \\
\hline LA & $12.0(10.2,13.6)$ & $12.7(11.7,13.2)$ & $13.7(10.0,15.0)$ & $11.8(9.9,12.2)$ & 0.30 & $11.8(9.9,14.7)$ & 0.36 \\
\hline ALA & $0.2(0.1,0.2)$ & $0.2(0.2,0.2)$ & $0.2(0.1,0.2)$ & $0.1(0.1,0.2)$ & 0.05 & $0.2(0.1,0.2)$ & 0.10 \\
\hline ARA & $20.1(18.3,23.1)$ & $22.2(19.1,23.1)$ & $19.9(18.3,21.1)$ & $19.8(17.8,23.0)$ & 0.63 & $19.9(17.8,23.0)$ & 0.34 \\
\hline DHA & $6.0(5.1,7.1)$ & $6.8(5.2,7.4)$ & $5.6(5.5,7.0)$ & $5.5(4.5,7.1)$ & 0.57 & $5.6(5.0,7.1)$ & 0.4 \\
\hline
\end{tabular}

ALA, $\alpha$-linolenic acid; ARA, arachidonic acid; DHA, docosahexaenoic acid; $L A$, linoleic acid.

a Levels reported as weight $\%(\mathrm{~g} / 100 \mathrm{~g})$. ${ }^{\mathrm{b}} \mathrm{Comparing}$ all three intervention groups. ${ }^{\mathrm{C} C o m p a r i n g ~ p l a c e b o}$ and any supplement.

Thirty patients were enrolled, and two deaths occurred prior to the first blood sampling. One infant in the low-dose group developed necrotizing enterocolitis totalis and one in the highdose group had severe respiratory failure and intraventricular hemorrhage (IVH). Surviving infants were born at a median of 26 wk gestation (interquartile range (IQR) 25-27) and $806 \mathrm{~g}$ (IQR 663-923). Maternal and infant perinatal characteristics at birth and measures of illness severity were similar in all three groups (Table 2) with infants in the high-dose group tending to be less mature and smaller at birth. Dosing administration (age at first dose: $2 \mathrm{~d}$ (IQR 2-3); age at last dose: $57 \mathrm{~d}$ (IQR 57-58)) and blood sampling (age at first sample: $16 \mathrm{~d}$ (IQR 15.5-17); age at second sample: $58 \mathrm{~d}$ (IQR 57-58)) for the entire cohort showed compliance with the protocol. No doses were interrupted due to apnea, bradycardia, or desaturation. One dose in one infant was not administered on the day of bowel perforation. Blood transfusions occurred in $75 \%$ of all infants; more of the infants receiving any DHA received RBC transfusions (Placebo: 50\%; Any: 89\%; $P=0.06)$.

Median growth velocity for all infants was $13 \mathrm{~g} / \mathrm{kg} / \mathrm{d}$ (IQR $11.6-14.1 ; P=0.68$ between groups). Infants receiving the high dose did not experience intestinal morbidity (Table 2). Rates of sepsis, bronchopulmonary dysplasia, and IVH were evenly distributed among the intervention groups; a trend toward higher rates of IVH appeared in the high-dose group. Three infants required intervention for retinopathy of prematurity.

\section{Nutritional Provisions and LCPUFA Levels by IVLE Duration}

Initiation of IVLE occurred earlier in the placebo group compared with infants receiving any DHA, but otherwise parenteral nutrition exposures were similar in all infants including duration of IVLE (Table 3). To understand contributions of feedings to LCPUFA status, we evaluated feeding patterns including type of feedings. Although only $54 \%$ received human milk for all feedings throughout hospitalization, most formula exposure occurred after the 8-wk study period. During the first $4 \mathrm{wk}$, infants rarely received formula as the percentage of feedings as breast milk was highest with a median value of $100 \%$. During the last $4 \mathrm{wk}$ of intervention, 26 infants received $\geq 65 \%$ of feedings as human milk, almost exclusively from their own mothers, while 2 infants received $<10 \%$ of feedings as human milk. Fifty-three percent of mothers consumed a DHA supplement during lactation and supplementation was similar between groups (Table 3). The use of supplement appears unrelated to RBC DHA ( $P$ $=0.9$ at 2 and $8 \mathrm{wk}$ ). Four infants received donor milk as some portion of feedings. Feedings were started at a median age of $4 \mathrm{~d}$ (IQR 3-6) and infants in the placebo group achieved full enteral nutrition (FEN) somewhat but not significantly earlier (Table 3). Exposure to a DHA-containing breast milk fortifier was evenly distributed among the groups (data not shown).

Thirteen infants had IVLE discontinued prior to the median $16 \mathrm{~d}$ ("Short") and achieved FEN significantly sooner than those with at least $16 \mathrm{~d}$ ("Long") exposure to IVLE (Short: $18 \mathrm{~d}$, IQR 17-22; Long: $41 \mathrm{~d}$, IQR 37-56; $P<0.001$ ). At $2 \mathrm{wk}$, infants with longer IVLE exposure showed higher RBC PL linoleic acid levels (Short: 11.8\%, IQR 10.7-12.4; Long: 13.5\%, IQR $11.7-14.4 ; P<0.001$ ) and $\alpha$-linolenic acid levels (Short: $0.2 \%$, IQR 0.1-0.2; Long: 0.2\%, IQR 0.2-0.3; $P<0.01$ ). ARA levels were not significantly different but DHA levels were lower with longer lipid exposure (Short: 5.2\%, IQR 4.8-6.1; Long: 4.2\%, IQR $4.0-4.5 ; P=0.008$ ). At $8 \mathrm{wk}$, linoleic acid remained higher with longer exposure (Short: 11.0\%, IQR 9.9-12.3; Long: $13.2 \%$, IQR $11.8-15.0 ; P=0.03$ ) and DHA remained lower (Short: 7.1\%, IQR 6.2-7.5; Long: 5.5\%, IQR 4.8-6.7; $P=0.03$ ).

\section{DISCUSSION}

Buccal administration of a concentrated formulation of DHA and ARA once per day did not affect RBC LCPUFA levels in ELBW infants. Although we found no effect of supplementation, infants had a better status of DHA and ARA during hospitalization and avoided the declines anticipated from a previous publication (19). In contrast to the earlier study, infants in this study received human milk as their enteral nutrition while on IVLE. All human milk contains DHA and ARA, but many of the infants' mothers consumed a supplement of DHA, which is known to increase milk DHA (20). Increased attention to providing human milk feedings for preterm infants may have contributed to these findings. 
Table 2. Infant and maternal characteristics (median IQR unless specified)

\begin{tabular}{|c|c|c|c|c|c|c|c|}
\hline & All, $n=28$ & Placebo, $n=10$ & Low dose, $n=9$ & High dose, $n=9$ & $P^{a}$ & Any DHA, $n=18$ & $P^{\mathrm{b}}$ \\
\hline Gestational age, wk & $26(25,27)$ & $26.5(25,28)$ & $26(26,27)$ & $25(25,25)$ & 0.14 & $25.5(25,27)$ & 0.56 \\
\hline Birth weight, $g$ & $806(663,923)$ & $852(800,910)$ & $771(700,950)$ & $730(655,820)$ & 0.48 & $730(655,935)$ & 0.31 \\
\hline Female gender, $n(\%)$ & $11(39)$ & $4(40)$ & $5(56)$ & $2(22)$ & 0.40 & $7(39)$ & 0.63 \\
\hline Small for gestational age, $n(\%)$ & $6(21)$ & $1(10)$ & $3(33)$ & $2(22)$ & 0.46 & $5(28)$ & 0.38 \\
\hline Multiple gestation, $n(\%)$ & $10(36)$ & $5(50)$ & $2(22)$ & $3(33)$ & 0.55 & $5(28)$ & 0.41 \\
\hline Preeclampsia, $n(\%)$ & $6(21)$ & $2(20)$ & $3(33)$ & $1(11)$ & 0.64 & $4(22)$ & 0.64 \\
\hline Completed antenatal steroids, $n$ (\%) & $23(82)$ & $8(80)$ & $7(78)$ & $8(89)$ & 0.30 & $15(83)$ & 0.10 \\
\hline Cesarean delivery, $n$ (\%) & $18(64)$ & $5(50)$ & $9(89)$ & $5(56)$ & 0.22 & $13(72)$ & 0.41 \\
\hline Received surfactant, $n$ (\%) & $24(86)$ & $8(80)$ & $8(89)$ & $8(89)$ & 1.0 & $16(89)$ & 0.60 \\
\hline SIP or NEC & $3(11)$ & $1(10)$ & $2(22)$ & 0 & 0.51 & $3(17)$ & 1.0 \\
\hline $\mathrm{IVH}$ & $7(25)$ & $2(20)$ & $1(11)$ & $4(44)$ & 0.31 & $5(28)$ & 1.0 \\
\hline ROP + Treatment & $3(11)$ & 0 & $1(1)$ & $2(22)$ & 0.29 & $3(17)$ & 0.53 \\
\hline Sepsis & $4(13)$ & $1(10)$ & $1(11)$ & $2(22)$ & 0.82 & $3(17)$ & 1.0 \\
\hline Cholestasis & $2(7)$ & 0 & 0 & $2(22)$ & 0.19 & $2(11)$ & 0.52 \\
\hline Length of stay, $d$ & $107(87,135)$ & $111(80,135)$ & $115(103,127)$ & $87(87,124)$ & 0.58 & $107(87,127)$ & 0.65 \\
\hline Discharge weight, $g$ & $3,105(2,635,3,775)$ & $3,378(2,580,3,885)$ & $3,457(2,930,3,530)$ & $2,690(2,315,3,140)$ & 0.28 & $43,003(2,690,3,530)$ & 0.58 \\
\hline Discharge weight $Z$-score & $-1.3(-1.9,-0.8)$ & $-1.1(-1.6,-0.4)$ & $-1.3(-2.2,-0.9)$ & $-1.8(-2.2,-1.1)$ & 0.4 & $-1.3(-2.2,-1.1)$ & 0.19 \\
\hline
\end{tabular}

BPD, bronchopulmonary dysplasia; DHA, docosahexaenoic acid; IVH, intraventricular hemorrhage; NEC, necrotizing enterocolitis; ROP, retinopathy of prematurity; SIP, spontaneous intestinal perforation; SNAPPE, Score for Neonatal Acute Physiology-Perinatal Extension.

a Comparing all three intervention groups. ${ }^{b}$ Comparing placebo and any supplement.

Table 3. Nutritional provisions for infants (median IQR unless specified)

\begin{tabular}{lccccccc}
\hline & All, $n=28$ & Placebo, $n=10$ & Low dose, $n=9$ & High dose, $n=9$ & $P^{\mathrm{a}}$ & Any DHA, $n=18$ & $P^{\mathrm{b}}$ \\
\hline Hour of life parenteral protein started & $3.5(2.8,4)$ & $3(2,4)$ & $4(3,4)$ & $4(3,5)$ & 0.36 & $4(3,5)$ & 0.18 \\
Hour of life IVLE started & $25.3(16.5,32.5)$ & $15(4,28)$ & $29(21,33)$ & $29(22,33)$ & 0.04 & $29(21,32.5)$ & 0.01 \\
Maximum dose parenteral protein $(\mathrm{g} / \mathrm{kg} / \mathrm{d})$ & $4(3.75,4)$ & $4(4)$ & $4(3.5,4)$ & $4(4)$ & 0.25 & $4(3.5,4)$ & 0.65 \\
Maximum dose parenteral lipid $(\mathrm{g} / \mathrm{kg} / \mathrm{d})$ & $2.01(2,3)$ & $2.9(2,3)$ & $2(1.2,2.8)$ & $2(2,2.9)$ & 0.18 & $2(2,2.9)$ & 0.07 \\
DOL parenteral protein stopped & $17(14,27)$ & $14.5(13,16)$ & $17(15,27)$ & $21(17,27)$ & 0.24 & $18(15,27)$ & 0.11 \\
DOL IVLE stopped & $16(12.5,25.5)$ & $13(11,16)$ & $17(13,27)$ & $17(16,24)$ & 0.22 & $17(14,27)$ & 0.11 \\
DOL initiation of enteral nutrition & $4(3,6)$ & $4(3,5)$ & $4(3,6)$ & $5(3,6)$ & 0.44 & $5(3,6)$ & 0.22 \\
DOL FEN achieved & $20(17.5,33.5)$ & $18(17,18)$ & $22(18,36)$ & $25(20,31)$ & 0.13 & $24(20,36)$ & 0.06 \\
Breast milk for all feedings, $n(\%)$ & $15(54)$ & $4(40)$ & $5(56)$ & $6(67)$ & 0.57 & $11(61)$ & 0.43 \\
Mother taking DHA supplement, $n(\%)$ & $16(53)$ & $5(50)$ & $5(50)$ & $6(60)$ & 0.72 & $11(55)$ & 0.81 \\
Any donor milk, $n$ (\%) & $4(13)$ & $2(20)$ & $2(22)$ & 0 & 0.51 & $2(11)$ & 0.60 \\
\hline
\end{tabular}

DHA, docosahexaenoic acid; DOL, day of life; FEN, full enteral nutrition; IVLE, intravenous lipid emulsion.

${ }^{a}$ Comparing all three intervention groups. ${ }^{b}$ Comparing placebo and any supplement. ${ }^{\circ}$ One unknown.

Inadequate endogenous production from the parent essential fatty acids, linoleic acid and $\alpha$-linolenic acid, warrants direct provision of ARA and DHA in preterm infants (21). Past methodologies to increase DHA and ARA delivery relied on maternal supplementation, sonication of FA with milk prior to feeding as well as direct administration via feeding tubes $(6,22,23)$. Adherence to the feeding tube and impaired intestinal absorption likely decreased the total dose delivered with those methods. Buccal absorption occurs for some nutrients and bioactive factors but it does not appear efficacious in regards to acyl fatty acids used in this study's formulation. Alternatively, the dosing in this 


\section{Articles $\mid$ Robinson etal.}

study may have been insufficient to impart changes in blood levels.

Dosing assignments in this study approximated amounts provided in commonly used feeding regimens (low dose) and estimates of fetal accretion rates (high dose) (8). Multiple factors may have prevented efficacy. Despite the presence and reported function of lingual lipase proximally $(24,25)$, cleavage of the acyl fatty acid may have been insufficient to affect levels. We expected some of the concentrated liquid to be swallowed with continued opportunity for gut metabolism. However, low pancreatic lipase function, a lack of coordination with feedings (which increases stomach acid production and facilitates lipase function), as well as the theoretical chance that the lipid adhered to the external surface of the enteric tube in the esophagus, all remain potential interfering factors. Infants tolerated the procedure well and the route of administration and small volumes appeared safe and might be considered for other nutrient interventions.

Despite no observed effect from the intervention, RBC PL DHA levels increased between the 2nd and 8th wk and no declines in ARA occurred. We speculate that key characteristics related to feeding of the participants promoted increases in DHA levels and stable ARA levels when, otherwise, this population accrues large deficits throughout hospitalization. Compared with our prior investigation, this population had higher exclusive breast milk use during the study period (1). Although observed rates of exclusive breast milk feedings throughout hospitalization might not be categorized as high, formula feedings were initiated most frequently after the intervention period. In that context, approximately half of mothers of infants participating in this study took DHA supplements during lactation, although we do not detect an apparent effect from this. DHA concentrations in breast milk reflect maternal intake (26). Population-based sampling shows marked variability in DHA yet many samples reveal concentrations much higher than that found in preterm infant formulas (27). Our previously analyzed samples from women in an urban Midwestern region of the United States showed DHA concentrations as high as $1 \%$, amounts almost five times greater than in preterm infant formulas (1). Although we did not collect milk during this study, we expected milk fed to infants in this study to have LCPUFA concentrations that match our prior measurements. One participating center used a breast milk fortifier that contained DHA; however, infants enrolled at the site not using a DHA-containing fortifier still showed increased levels over time. The observed increase in DHA and stable ARA status over time were unexpected findings; we can only speculate that these patterns are attributable to high rates of human milk feedings. With ongoing efforts by clinicians to increase human milk use in NICU's and the possibility of continued increases in mother's taking DHA supplements, we support that future investigations involving LCPUFA supplementation in the context of human milk-fed infants must involve sampling of human milk.
Infants assigned to placebo reached FEN at a median $6 \mathrm{~d}$ sooner than infants receiving DHA supplements and had slightly higher 8-wk DHA levels. Overall, these are consistent findings which support improved DHA status resulting from breast milk feedings. In consideration of these increases, $8 \mathrm{wk}$ values still did not approximate a theoretical target level of 9\%, a plateau level documented in breast milk-fed term infants whose mothers consumed DHA supplements during lactation (28). We note that randomization placed fewer small-for-gestational-age (SGA) infants in the placebo group which may have contributed to the earlier achievement of FEN. Enteral nutrition advancement in SGA infants often occurs more slowly than infants born at an appropriate weight for age (29).

The characteristics of this ELBW cohort included multiplegestation pregnancies, pregnancy complications including preeclampsia and rates of SGA status higher than the expected $10 \%$. Although in-utero DHA and ARA transfer in these pregnancies may have been reduced (30), this study focused on postnatal provisions and absorption. To be sparing in blood collections in a vulnerable population, and based on the fact that levels at 2 and $8 \mathrm{wk}$ should reveal effects of supplements, we excluded blood sampling at birth in this feasibility trial. We previously measured LCPUFA levels at birth and throughout hospitalization in ELBW infants, observing that postnatal levels from $2 \mathrm{wk}$ until $8 \mathrm{wk}$ correlated with nutritional provisions (1). We believe these pregnancy-related circumstances would not be expected to impact postnatal absorption and future, larger studies will be powered to account for relevant factors including SGA status.

We validated our earlier findings that the duration of IVLE exposure affects DHA levels (1). Differences appeared at $2 \mathrm{wk}$ of age, emphasizing early detrimental effects of current nutritional provisions. Perhaps more notable, IVLEs in infants with longer exposure were discontinued at a median age of $31 \mathrm{~d}$ and yet the DHA levels at 8 wk of age remained significantly lower. This late effect highlights the compounding and lasting effects of prolonged exposure to a lipid source lacking DHA followed by suboptimal provisions in feedings.

Inadequate ARA and DHA contribute to impaired growth $(2,31)$, but investigators must continue to assess for negative effects of increased doses on growth. The high-dose group was discharged at a smaller weight than the other groups. In review of their gestational age at birth, birth weight, and length of stay, we believe that this reflects their clinical circumstances and not an effect from supplements, particularly in the face of no detectable uptake of the supplements.

ELBW infants represent a population at high risk of suboptimal DHA and ARA provisions. Early feedings appear safe in these infants yet some feeding protocols involve the withholding of initial feedings for 7-14 d in ELBW infants (32). Slow feeding advances delay enteral provisions even if a mother's milk DHA concentration happens to be high. Ongoing investigations of methods to promptly and adequately provide these critical LCPUFA are necessary. These methodologies should ideally operate independently of feeding status. Access to IVLE 
that contains these LCPUFA will aid in early provision that is independent of feeding status. It is noteworthy, though, that IVLE formulations containing longer chain fatty acids do not mimic amounts transferred in utero and as compared with breast milk contain higher concentrations of unknown significance (9).

In conclusion, DHA and ARA administration to the buccal mucosa of ELBW infants, as formulated into high oleic sunflower oil, did not affect RBC PL LCPUFA levels in this study. Nonetheless, we observed an unexpected increase in DHA and stable ARA levels in ELBW infants over their first $8 \mathrm{wk}$. This was presumably attributable to factors related to breast milk feedings and not to buccal administration of a supplement, although even in breast milk-fed infants, the levels remained below achievable values in term infants. Eliminating deficits in these important LCPUFA in preterm infants should be expected to improve growth and reduce morbidity. The best methodology of supplementation remains to be determined. Continued attention to optimizing prompt feeding of breast milk with sufficient DHA in the maternal diet and additional infant supplementation appears to be an important foundation for both clinical and research interventions aimed at improving LCPUFA delivery to preterm infants.

\section{METHODS}

We prospectively screened and then randomized infants born $<1,000 \mathrm{~g}$ and at gestational ages $<34 \mathrm{wk}$ with informed, signed consent by parent or legal guardian before $72 \mathrm{~h}$ of age. Exclusion criteria included metabolic disorders, gastrointestinal anomalies, or being deemed inappropriate for study enrollment by the attending neonatologist. Study enrollment commenced in October 2013, and the final participant completed the study supplement in March 2015. Institutional Review Boards of NorthShore University HealthSystem, Northwestern University, and Lurie Children's Hospital approved the study.

\section{Randomization and Supplement Dosing}

Randomization was computer generated, and participants were assigned to receive $0.5 \mathrm{ml} / \mathrm{kg}$ daily of one of three supplements involving the use of two supplement oils to formulate doses $(100 \%$ high oleic sunflower oil and ARA $240 \mathrm{mg} / \mathrm{ml}+$ DHA $120 \mathrm{mg} / \mathrm{ml}$; DSM Nutritional Products): (i) Placebo without DHA, 100\% high oleic sunflower oil; (ii) Low-dose DHA, $20 \mathrm{mg} / \mathrm{kg} / \mathrm{d}$ with ARA $40 \mathrm{mg} /$ $\mathrm{kg} / \mathrm{d}$; and (iii) High-dose DHA, $60 \mathrm{mg} / \mathrm{kg} / \mathrm{d}$ with ARA $120 \mathrm{mg} / \mathrm{kg} / \mathrm{d}$. Group assignment and dose preparation were performed by research pharmacy staff to maintain blinding of investigators, clinical staff, and participating families to the assignment group. Multiple births were assigned to the same group. The daily dose was dispensed in two syringes, half of the dose in each syringe. Trained neonatal nurses placed the tip of the syringe alongside the buccal mucosa and administered the syringe volume over $\leq 2 \mathrm{~min}$. Administration was paused until after recovery if apnea, bradycardia, or desaturation occurred. The procedure was repeated on the opposite side with the second syringe. Routine oropharyngeal suctioning by clinical staff was withheld for at least $1 \mathrm{~h}$ after administration if clinically appropriate. The intervention continued through $8 \mathrm{wk}$ of age or discharge, whichever occurred first.

\section{Outcomes and Clinical Measures}

The primary outcome was RBC PL DHA levels at $2 \mathrm{wk}$ after randomization. Secondary outcomes included all other LCPUFA levels at 2 and $8 \mathrm{wk}$, or at time of discharge if sooner. Demographic data collected were standard maternal and infant characteristics including fetal and neonatal growth status at birth, maternal DHA supplementation in pregnancy and lactation, and measures of severity of illness (Score for Neonatal Acute Physiology-Perinatal Extension II (33)).

Clinical outcomes were collected and included: respiratory distress syndrome requiring surfactant, IVH, periventricular leukomalacia, spontaneous intestinal perforation or necrotizing enterocolitis, bronchopulmonary dysplasia (oxygen requirement at $36 \mathrm{wk}$ postmenstrual age), retinopathy of prematurity requiring intervention, sepsis (positive blood culture thought not to be a contaminant by primary team), cholestasis, and mortality. RBC transfusions and hospital stay were recorded.

Nutritional data collected included details of parenteral nutrition provisions, feeding initiation, and timing of FEN (enteral feedings provide $\geq 110 \mathrm{kcal} / \mathrm{kg} / \mathrm{d}$ ). Nutritional management was at the discretion of the attending neonatologist, as were all other aspects of clinical management. Centers initiated parenteral dextrose and protein solutions promptly after birth. IVLE (Intralipid, 20\% solution; Fresenius Kabi) began within $48 \mathrm{~h}$ of age. Feedings started when deemed appropriate $(\leq 20 \mathrm{ml} / \mathrm{kg} / \mathrm{d})$ and advanced at $20 \mathrm{ml} / \mathrm{kg} / \mathrm{d}$ as tolerated. Maternal breast milk was provided when available, and donor breast milk used for supplementation until infants weighed 1,500 g.

\section{Blood Sampling}

Whole blood was drawn at 2 and 8 wk of dosing and collected into EDTA-containing phlebotomy tubes for RBC LCPUFA analysis. $\mathrm{RBCs}$ were separated and stored under nitrogen at $-80^{\circ} \mathrm{C}$ or on dry ice in transfer until fatty acid analysis. Samples were analyzed within 20 mo of collection. The staff completing assays was masked to the assignment groups.

\section{Preparation of RBC PLs}

Total lipids in RBC samples were extracted according to a modified procedure of Folch et al. (34), and the PLs were isolated by thin layer chromatography (Silica gel G plates, $250 \mu \mathrm{m}$ thickness; Analtech, Newark, DE) with an 80:20:1 hexane-diethyl ether-acetic acid solvent (35). PL bands were transmethylated with $1 \mathrm{ml}$ boron trifluoride (Sigma-Aldrich, St. Louis, MO), and the resulting fatty acid methyl esters were extracted with pentane (36); pentane was vaporized under nitrogen and the sample dissolved in dichloromethane for storage at $-80^{\circ} \mathrm{C}$ until analysis.

\section{Analysis of RBC PL LCPUFA}

Fatty acid methyl esters were separated by gas chromatography in a $6890 \mathrm{~N}$ gas chromatograph (Agilent Technologies, Santa Clara, CA) on an SP-2560 capillary column $\left(\mathrm{L} \times \mathrm{I}\right.$.D. $100 \mathrm{~m} \times 0.25 \mathrm{~mm}, \mathrm{~d}_{\mathrm{f}} 0.20$ $\mu \mathrm{m}$; Supelco). Carrier gas was helium at $1.2 \mathrm{ml} / \mathrm{min}$, and the split ratio was $25: 1$. Column temperature was held constant at $140^{\circ} \mathrm{C}$ for $5 \mathrm{~min}$ then advanced at $4^{\circ} \mathrm{C} / \mathrm{min}$ for $25 \mathrm{~min}$ and held constant at $240^{\circ} \mathrm{C}$ for $12 \mathrm{~min}$. Injector and detector (flame ionization) were programmed at $260^{\circ} \mathrm{C}$. Individual fatty acids were identified by comparing retention times with fatty acid mixtures (Supelco 37 and PUFA 2 , Sigma-Aldrich) and weight percent determined by comparison of the area under the curve (OpenLab ChemStation C.01.06, Agilent Technologies) to weighed standards (Supelco 37).

\section{Statistical Analyses}

Using levels from our initial investigation in a similar population (1) for sample size calculations, we determined that a sample size of 10 in each intervention group would allow detection of an increase in RBC PL DHA levels from 3.6 weight (wt) \%, SD 1 at $2 \mathrm{wk}$ of age to $5 \mathrm{wt} \%$, SD 1 with power $=0.8$ and $\alpha=0.05$. Nonparametric tests were used for all statistical analyses. Due to past evidence that duration of IVLE impacts LCPUFA levels and to measure effects of IVLE duration, the median IVLE exposure in the entire cohort was calculated to be $16 \mathrm{~d}$ in order to stratify infants based on shorter or longer IVLE exposures. Two-group comparisons of LCPUFA levels were performed based on IVLE duration. Gender specific standard deviation $(Z)$ scores for birth and discharge weight were calculated using the Fenton curve (37). Analyses were performed using Stata v12.1 (StataCorp), and statistical significance was defined using $\alpha=0.05$. All fatty acid levels are reported as wt $\%(\mathrm{~g} / 100 \mathrm{~g})$.

\section{STATEMENT OF FINANCIAL SUPPORT}

Mead Johnson Nutrition provided the supplements used in this trial as well as funding to support trial implementation including salary support for D.T.R 
and B.F. There has been no study sponsorship involvement in any of the following areas: (i) study design; (ii) the collection, analysis, and interpretation of data; (iii) the writing of the report; and (iv) the decision to submit the paper for publication. The first draft was written by D.T.R and B.F., and no authors received an honorarium, grant, or any form of payment for the production of this manuscript. This trial was registered prior to first enrollment at ClinicalTrials.gov, registration number NCT01955044.

\section{REFERENCES}

1. Robinson DT, Carlson SE, Murthy K, Frost B, Li S, Caplan M. Docosahexaenoic and arachidonic acid levels in extremely low birth weight infants with prolonged exposure to intravenous lipids. J Pediatr 2013;162:56-61.

2. Clandinin MT, Van Aerde JE, Merkel KL, et al. Growth and development of preterm infants fed infant formulas containing docosahexaenoic acid and arachidonic acid. J Pediatr 2005;146:461-8.

3. Manley BJ, Makrides M, Collins CT, et al.; DINO Steering Committee. High-dose docosahexaenoic acid supplementation of preterm infants: respiratory and allergy outcomes. Pediatrics 2011;128:e71-7.

4. Martin CR, Dasilva DA, Cluette-Brown JE, et al. Decreased postnatal docosahexaenoic and arachidonic acid blood levels in premature infants are associated with neonatal morbidities. J Pediatr 2011;159:743-749.e1-2.

5. Carlson SE, Werkman SH, Rhodes PG, Tolley EA. Visual-acuity development in healthy preterm infants: effect of marine-oil supplementation. Am J Clin Nutr 1993;58:35-42.

6. Henriksen C, Haugholt K, Lindgren M, et al. Improved cognitive development among preterm infants attributable to early supplementation of human milk with docosahexaenoic acid and arachidonic acid. Pediatrics 2008;121:1137-45.

7. Lapillonne A, Eleni dit Trolli S, Kermorvant-Duchemin E. Postnatal docosahexaenoic acid deficiency is an inevitable consequence of current recommendations and practice in preterm infants. Neonatology 2010;98: 397-403.

8. Lapillonne A, Jensen CL. Reevaluation of the DHA requirement for the premature infant. Prostaglandins Leukot Essent Fatty Acids 2009;81: $143-50$.

9. Vanek VW, Seidner DL, Allen P, et al.; Novel Nutrient Task Force, Intravenous Fat Emulsions Workgroup; American Society for Parenteral and Enteral Nutrition (A.S.P.E.N.) Board of Directors. A.S.P.E.N. position paper: clinical role for alternative intravenous fat emulsions. Nutr Clin Pract 2012;27:150-92.

10. Lindquist $\mathrm{S}$, Hernell $\mathrm{O}$. Lipid digestion and absorption in early life: an update. Curr Opin Clin Nutr Metab Care 2010;13:314-20.

11. Rodriguez NA, Meier PP, Groer MW, Zeller JM, Engstrom JL, Fogg L. A pilot study to determine the safety and feasibility of oropharyngeal administration of own mother's colostrum to extremely low-birth-weight infants. Adv Neonatal Care 2010;10:206-12.

12. Thibeau S, Boudreaux C. Exploring the use of mothers' own milk as oral care for mechanically ventilated very low-birth-weight preterm infants. Adv Neonatal Care 2013;13:190-7.

13. Böhles H, Bieber MA, Heird WC. Reversal of experimental essential fatty acid deficiency by cutaneous administration of safflower oil. Am J Clin Nutr 1976;29:398-401.

14. Skolnik P, Eaglstein WH, Ziboh VA. Human essential fatty acid deficiency: treatment by topical application of linoleic acid. Arch Dermatol 1977;113:939-41.

15. Gura KM, Parsons SK, Bechard LJ, et al. Use of a fish oil-based lipid emulsion to treat essential fatty acid deficiency in a soy allergic patient receiving parenteral nutrition. Clin Nutr 2005;24:839-47.

16. Birudaraj R, Berner B, Shen S, Li X. Buccal permeation of buspirone: mechanistic studies on transport pathways. J Pharm Sci 2005;94:70-8.

17. Thakur RA, Michniak BB, Meidan VM. Transdermal and buccal delivery of methylxanthines through human tissue in vitro. Drug Dev Ind Pharm 2007;33:513-21.
18. Onuki $\mathrm{Y}$, Morishita M, Takayama K, et al. In vivo effects of highly purified docosahexaenoic acid on rectal insulin absorption. Int J Pharm 2000;198:147-56.

19. Carlson SE, Cooke RJ, Rhodes PG, Peeples JM, Werkman SH, Tolley EA. Long-term feeding of formulas high in linolenic acid and marine oil to very low birth weight infants: phospholipid fatty acids. Pediatr Res 1991;30:40412.

20. Jensen CL, Maude M, Anderson RE, Heird WC. Effect of docosahexaenoic acid supplementation of lactating women on the fatty acid composition of breast milk lipids and maternal and infant plasma phospholipids. Am J Clin Nutr 2000;71(1 Suppl):292S-9S.

21. Uauy R, Mena P, Wegher B, Nieto S, Salem N Jr. Long chain polyunsaturated fatty acid formation in neonates: effect of gestational age and intrauterine growth. Pediatr Res 2000;47:127-35.

22. Liu CC, Carlson SE, Rhodes PG, Rao VS, Meydrech EF. Increase in plasma phospholipid docosahexaenoic and eicosapentaenoic acids as a reflection of their intake and mode of administration. Pediatr Res 1987;22:292-6.

23. Makrides M, Gibson RA, McPhee AJ, et al. Neurodevelopmental outcomes of preterm infants fed high-dose docosahexaenoic acid: a randomized controlled trial. JAMA 2009;301:175-82.

24. Smith LJ, Kaminsky S, D'Souza SW. Neonatal fat digestion and lingual lipase. Acta Paediatr Scand 1986;75:913-8.

25. Salzman-Mann C, Hamosh M, Sivasubramanian KN, et al. Congenital esophageal atresia: lipase activity is present in the esophageal pouch and stomach. Dig Dis Sci 1982;27:124-8.

26. Insull W Jr, Hirsch J, James T, Ahrens EH Jr. The fatty acids of human milk. II. Alterations produced by manipulation of caloric balance and exchange of dietary fats. J Clin Invest 1959;38:443-50.

27. Brenna JT, Varamini B, Jensen RG, Diersen-Schade DA, Boettcher JA, Arterburn LM. Docosahexaenoic and arachidonic acid concentrations in human breast milk worldwide. Am J Clin Nutr 2007;85:1457-64.

28. Gibson RA, Neumann MA, Makrides M. Effect of increasing breast milk docosahexaenoic acid on plasma and erythrocyte phospholipid fatty acids and neural indices of exclusively breast fed infants. Eur J Clin Nutr 1997;51:578-84.

29. Kempley S, Gupta N, Linsell L, et al.; ADEPT Trial Collaborative Group. Feeding infants below 29 weeks' gestation with abnormal antenatal Doppler: analysis from a randomised trial. Arch Dis Child Fetal Neonatal Ed 2014;99:F6-F11.

30. Wadhwani N, Patil V, Pisal H, et al. Altered maternal proportions of long chain polyunsaturated fatty acids and their transport leads to disturbed fetal stores in preeclampsia. Prostaglandins Leukot Essent Fatty Acids 2014;91:21-30.

31. Carlson SE, Werkman SH, Peeples JM, Cooke RJ, Tolley EA. Arachidonic acid status correlates with first year growth in preterm infants. Proc Natl Acad Sci USA 1993;90:1073-7.

32. Viswanathan S, McNelis K, Super D, Einstadter D, Groh-Wargo S, Collin M. Standardized slow enteral feeding protocol and the incidence of necrotizing enterocolitis in extremely low birth weight infants. JPEN J Parenter Enteral Nutr 2015;39:644-54.

33. Richardson DK, Corcoran JD, Escobar GJ, Lee SK. SNAP-II and SNAPPEII: simplified newborn illness severity and mortality risk scores. J Pediatr 2001;138:92-100.

34. Folch J, Lees M, Sloane Stanley GH. A simple method for the isolation and purification of total lipids from animal tissues. J Biol Chem 1957;226:497509.

35. Dodge JT, Phillips GB. Composition of phospholipids and of phospholipid fatty acids and aldehydes in human red cells. J Lipid Res 1967;8:667-75.

36. Morrison WR, Smith LM. Preparation of fatty acid methyl esters and dimethylacetals from lipids with boron fluoride-methanol. J Lipid Res 1964;5:600-8.

37. Fenton TR, Kim JH. A systematic review and meta-analysis to revise the Fenton growth chart for preterm infants. BMC Pediatr 2013;13:59. 